\title{
RAZÃO, REALIDADE, COMPAIXÃO
}

\author{
RAGIONE, REALTÀ, COMPASSIONE
}

Paul Gilbert*
Tradução do italiano: Ibraim Vitor de Oliveira**

\section{RESUMO:}

A contemporaneidade, de fato, atribui às paixões a capacidade de conceder acesso à realidade, aliás, de construir a realidade. Porém, em se tratando da oposição entre razão e paixão, a discussão é bastante antiga, já era clássica não só em filosofia, mas também na educação. A razão, "objetiva", seria a garantia da paz civil; a paixão, "subjetiva", seria, contrariamente, causa de muitos distúrbios sociais. A partir de Platão, a primeira é chamada a confrontar-se com a realidade, vale dizer, com os elementos estáveis da experiência humana. A razão é, por princípio, mestra de si, ativa e impassível com relação ao que é flexível e não se deixa tocar por nada que possa fragilizá-la ou mudá-la. A segunda, diversamente, é pouco confiável, porque sempre em movimento e com absoluta dependência dos eventos que a impulsionam casualmente; ela é essencialmente reativa. Por isso, para a tradição, o ideal de homem, a melhor expressão da sua identidade e da sua dignidade, se situa na sua capacidade de realizar a própria vontade, de não ser enganado por paixões fantásticas e inconstantes. Trata-se de uma autodeterminação, em outros termos, de inteira possessão de si.

PALAVRAS-CHAVE: Paixão. Razão. Realidade. Compaixão. Interlocução

\section{RIASSUNTO:}

La contemporaneità attribuisce infatti alle passioni la capacità di dare accesso alla realtà, di costituire anzi la realtà. L'opposizione era però classica, in filosofia ma anche nell'educazione, tra la ragione e la passione: la prima, 'oggettiva', garantirebbe la pace civile; la seconda, 'soggettiva', sarebbe invece causa di molti disturbi sociali. Da Platone in poi, la prima è chiamata a confrontarsi con le realtà, vale a dire con gli elementi stabili dell'esperienza umana: è per principio maestra di sé, attiva e impassibile verso ciò che è fluttuante, non si lascia toccare da niente che possa renderla fragile o cambiarla; la seconda, invece, poco affidabile, perché sempre movimentata e dipendente dagli eventi che la sfiorano casualmente, è essenzialmente reattiva. L'ideale dell'uomo, l'espressione migliore della sua identità e della sua dignità, si situa perciò nella sua capacità di realizzare la propria volontà, di non essere ingannato da passioni fantastiche e incostanti; è l'auto-determinazione o la possessione intera di sé.

PAROLE CHIAVE: Passione. Ragione. Realtà. Compassione. Interlocuzione.

\footnotetext{
* Paul Gilbert, filósofo belga (de Charleroi, 1945), foi professor titular da Cátedra de Metafísica da Pontificia Università Gregoriana de Roma, de 1986 a 2014, e Professor convidado em Paris, Kinshasa, América Latina. Detentor de vasta produção filosófica, em especial na área de metafísica, ontologia e fenomenologia, Paul Gilbert possui vários artigos e livros traduzidos no Brasil, dentre os quais, A simplicidade do principio e $A$ paciência de ser, ambos pela Loyola. Seu último livro, Violence et compassion, 2009, teve grande repercussão no cenário filosófico europeu. Recentemente, foi homenageado com um dossiê específico, intitulado Permanência da metafísica. O dossiê, que demarca o horizonte filosófico de Paul Gilbert, foi organizado por Ibraim Vitor de Oliveira e Evanildo Costeski e publicado pela revista Argumentos da Universidade Federal do Ceará; encontra-se disponível em http://www.periodicos.ufc.br/argumentos/issue/view/525.

** Doutor em Filosofia. Professor de filosofia na PUC Minas. E-mail: ibraimvitorivo@gmail.com. Texto original em italiano: GILBERT, P. Ragione, realtà, compassione. In: GILBERT, P. (org.). Passione. Indagini filosofiche tra ontologia e violenza. Assisi: Cittadella, 2007, p. 155-179.
} 


\section{INTRODUÇÃO}

O presente artigo afronta o problema da relação entre as paixões e a realidade. A situação espiritual contemporânea parece opor-se completamente ao modo como tradição se relaciona com o tema. A contemporaneidade, de fato, atribui às paixões a capacidade de conceder acesso à realidade, aliás, de construir a realidade. Porém, em se tratando da oposição entre razão e paixão, a discussão é bastante antiga, já era clássica não só em filosofia, mas também na educação. A razão, “objetiva", seria a garantia da paz civil; a paixão, "subjetiva”, seria, contrariamente, causa de muitos distúrbios sociais. A partir de Platão, a primeira é chamada a confrontar-se com a realidade, vale dizer, com os elementos estáveis da experiência humana. A razão é, por princípio, mestra de si, ativa e impassível com relação ao que é flexível e não se deixa tocar por nada que possa fragilizá-la ou mudá-la. A segunda, diversamente, é pouco confiável, porque sempre em movimento e com absoluta dependência dos eventos que a impulsionam casualmente; ela é essencialmente reativa. Por isso, para a tradição, o ideal de homem, a melhor expressão da sua identidade e da sua dignidade, se situa na sua capacidade de realizar a própria vontade, de não ser enganado por paixões fantásticas e inconstantes. Trata-se de uma autodeterminação, em outros termos, de inteira possessão de si.

A cultura ocidental construiu para si esse modelo de humanidade, e, além disso, o colocou como norma para tudo o que considerou realidade verdadeira. Que a realidade seja a ideia platônica ou a substância aristotélica, isso de fato não interessa. Aqui, o importante é que a realidade não dependa das circunstâncias da vida, mas seja presente, acessível a todos e totalmente imutável. Assim, a realidade deverá ser encontrada por todos os que submetem suas investigações e pesquisas a procedimentos universalmente válidos, em especial, à lógica formal, cujas regras fundamentais estão impressas em cada mente. A ideia de realidade deve, então, estar ligada ao que não é próprio de alguém, para poder ser colhida igualmente por todos e mediante métodos que, depois de descartada qualquer marca de subjetividade, darão prova de fecundidade. A realidade é o que de nada depende, de ninguém; é o que, por si mesmo, resiste a tudo.

A concepção de realidade na história da filosofia se produz com matizes muito variados. Para a antiguidade, a realidade era dada imediatamente na experiência que cada qual acreditava fazer diretamente do mundo. Por sua vez, a Modernidade mostrou que a realidade é construída; apesar das ingênuas pretensões do positivismo, ela não pode ser entendida em conformidade com o aparecer imediato do que é. Não é possível desconsiderar que, aqui, a 
tradição filosófica incorre em verdadeira incoerência: primeiramente, faz com que todo o processo intelectivo tenha início com a experiência sensível entendida como contato direto com o que é ${ }^{1}$, e, depois, insiste em evidenciar que essa mesma experiência não seja confiável, mas verificada. Como explicar tamanha estranheza da interpretação tradicional da dinâmica do saber? Um dito clássico afirma que, no saber, tudo procede dos sentidos, salvo o próprio saber. Essa afirmação, inclusive, poderia até sustentar a interpretação, obviamente errada, do saber para o positivismo, o qual não quer reconhecer outra realidade além da sensível. Mas não é o caso. O privilégio que a filosofia clássica dá à experiência sensível não procede, como acontece no positivismo, de uma exigência que encontra em si mesma o modelo excelente do constitutivo da realidade, isto é, sua resistência.

É reconhecido o fato de que o saber intelectual não pode ir adiante sem assumir um modelo proveniente de algum domínio da cultura utilizado como guia para se progredir em outros domínios ${ }^{2}$. Por exemplo, hoje em dia, os modelos matemáticos prestam serviço a todas as ciências físicas. Diante disso, busca-se questionar o motivo pelo qual a experiência sensível foi quase unanimemente escolhida como modelo para se descobrir a essência da realidade. A realidade é o que resiste. Se se considera que a experiência sensível resiste, ela será escolhida como modelo para interpretar a excelência do ato cognitivo. Sabe-se, porém, que nos dias atuais a ciência manipula os sensíveis para melhor conhecê-los, logo, eles não manifestam imediatamente suas realidades; pelo contrário, eles pouco resistem aos procedimentos de um cientista competente. Mesmo assim, a exigência de realidade permanece a da resistência. Mas a verdadeira resistência não pode ser representada pela experiência sensível...: chega-se ao incontrovertível.

\section{RAZÃO E REALIDADE}

Mediante a razão, se pode dizer que a experiência sensível oferece um modelo possível para se intender o que é a realidade. Sem a razão, haveria a necessidade de se supor a existência de que tal afirmação fosse inspecionada e analisada por alguma outra instância cognoscitiva. A experiência sensível deve ser julgada conveniente para cumprir a tarefa que dela se espera, vale dizer, ter a função de um modelo suscetível para guiar a interpretação que a mente faz do seu próprio caminho cognoscitivo. Todas essas exigências supõem que o

\footnotetext{
${ }^{1}$ Ver Aristotele (Metafisica, I, 1).

${ }^{2}$ Ver Ricoeur (1976, p. 315-324).
}

Sapere aude - Belo Horizonte, v. 10 - n. 19, p. 122-144, Jan./Jun. 2019 - ISSN: 2177-6342 
modelo, que é a experiência sensível, seja reconhecido como válido, isto é, se conheça previamente aquilo do qual será modelo. Ora, a sensibilidade não é capaz de colher por si mesma a realidade; as experiências de ilusões óticas demonstram suficientemente esse dado. Para cobrir tal incapacidade, trabalha-se no aperfeiçoamento dos laboratórios de física, nos quais se retira um aspecto do sensível e dele se elimina qualquer tipo de interferência.

\subsection{A experiência sensível}

Pergunta-se, mais uma vez: de onde provém o privilégio, tradicionalmente reconhecido, dado à experiência sensível? É obvio que a experiência sensível deve ser julgada fora de si mesma; isso, por princípio, já coloca em dúvida a sua competência com relação ao problema analisado. Em outros termos, a instância cognoscitiva, que por um lado atribui à experiência sensível certa competência, por outro, a nega; sobrepõem-se ao procedimento um aspecto que a sensibilidade ignora, porque provém da própria experiência espiritual. Projetase necessariamente, de antemão, o que se procura, a saber, o constitutivo da realidade que se reconhece como a resistência do que está unido a si, idêntico a si de um modo necessário e incontrovertível. A pergunta, então, poderia ser assim formulada: por que essa instância superior realiza semelhante tática, uma transferência que se ilude quanto à constituição da realidade?

Preliminarmente, o que se julga na experiência sensível é a relação entre o percetor (o sujeito que percebe) e o percebido (o que se percebe). Essa relação terá muitas formas, por exemplo, de igualdade, de adequação, de semelhança, de diferença ou, ainda, de oposição. $\mathrm{O}$ julgamento de que agora se fala supõe que as respectivas contribuições entre percetor e percebido estejam bem isoladas para, depois, serem recompostas, mesmo se a experiência assim diluída pela análise de seus componentes essenciais seja vivida como se fosse unida. $\mathrm{O}$ percetor, ao ser submetido às circunstâncias da sua individualidade, deve organizar o pensamento de tal maneira que a realidade seja libertada da sua influência: livre de qualquer modificação subjetiva. Parece, então, importante, para se julgar corretamente a percepção da realidade, que as contribuições do perceptor sejam determinadas antecipadamente e circunscritas com precisão, para que não intervenham na interpretação do presentificar-se da realidade sensível.

Um dos principais critérios utilizados nessa perspectiva é o temporal, considerando duas distinções nas coisas: de um lado, o que se move e, do outro, seus aspectos estáveis, aos 
quais se atribuirá a capacidade de manifestar a mais radical realidade. Estaremos, assim, na presença de dois modos diferentes do tempo. Essa diferença entre o tempo do que acontece acidentalmente nas coisas (a sua "temporalidade", pode-se dizer) e o tempo da substância que se quer estável (aqui, diversamente, se fala de "duração") é essencial para se julgar sobre o que constitui a realidade. Aqui, a experiência sensível é analisada de tal modo que se possam determinar os elementos da substância e os diferentes momentos do seu aparecer em presença, do seu "fenomenizar-se". Na tradição filosófica, alguns desses modos - os que pertencem à essência da substância - são, porém, de ordem transcendental, são condições que se impõem espiritualmente ao percetor, a fim de que ele possa colher o que é independentemente dele. Mas essa interpretação da duração da realidade ou da substância repousa, de novo, sobre o saber que a mente já possui da própria identidade mediante a multiplicidade de suas operações: sabe-se, de antemão, o que é permanecer.

A interpretação da experiência sensível passa, então, habitualmente da ideia de identidade para a ideia de permanência, ou melhor, de imobilidade. O que muda, de fato, não tem uma identidade clara; será de um modo agora e, de outro, depois. A ideia de muitos filósofos clássicos é a seguinte: o que muda sofre a ação de um outro. Por si, uma substância não mudaria. Assim, a ideia de imobilidade é acompanhada pela de "não padecimento". Consequentemente, dizem os clássicos, o que está na própria identidade, logo, que nada sofre será pura ação, ato puro. Por isso, um ato puro é também imóvel, indiferente a tudo o que lhe poderia acontecer; não depende de nada para ser o que é. Esse conjunto de ideias poderá ensejar algo de paradoxal: o ato e a imobilidade parecem estar juntos. Mas se poderia pensar que o ato entendido dessa forma não se expande para fora de si, em outros termos, é um ato "intransitivo"; é o ato da práxis, que Aristóteles distinguia do ato da poiēsis. Em especial, a distinção se situava no fato de que o ato da práxis não se submete às condições do que é outro de si: a sua energia é ele próprio. Nesse caso, a ideia de imobilidade passa para a ideia de constância no tempo e, assim, se sai do paradoxo. $\mathrm{O}$ ato primeiro é sempre idêntico à sua própria energia, nesse sentido, imóvel.

\subsection{Inteligência da consciência}

Passemos agora para outra análise. Examinemos sobre a inteligência que a consciência tem de si, vale dizer, a cartesiana experiência reflexiva. Realmente, não existe uma

\footnotetext{
${ }^{3}$ Ver Gilbert (1997, p. 47-59).
} 
consciência efetiva de si que não seja em ato. Por certo, a tomada de consciência é frequentemente provocada, mas, seja como for, a consciência provocada será chamada diante de si para tomar posse da sua identidade, para reconhecer a sua continuidade ou duração estável, a própria responsabilidade de si, independentemente da causa que provocou a autoconsciência. A consciência, sempre ativa nos seus compromissos no mundo, pode experimentar ao mesmo tempo o reconhecimento do dinamismo de sua unidade interior. A expressão de Descartes "cogito, sum" significa que, quando penso em algo, coloco-me em atividade sem me transformar na coisa pensada. Para nós, é indispensável reconhecer semelhante presença interior do cogito a si mesmo: pensar em algo que ele próprio não é. Assim, esse dito cartesiano exprime de modo esplêndido a exigência de não controvertibilidade. O termo sum, de fato, significa o surgir do pensante que, em um ato percebido conscientemente, pensa algo que ele não é. Isso significa dizer que em todo ato de pensar, posso acessar a consciência de uma autopresença ontológica, ativa, em efetivo ato.

Não é incomum se deparar com manuais que se valem daquela distinção entre os aspectos acidental e substancial na coisa sensível. Contudo, aqui não se pode pensar que a substância seja imóvel, no sentido de que seria impossível uma modificação da sua natureza. O ato duradouro não é imóvel, mas pode passar de um estado para outro; ele não permanece fechado em sua "inseidade", no estado de um "instante". "Permanece", no sentido de ficar "constante". A preposição "per" significa justamente, de acordo com a linguística, a constância do "manere" (do "durar"). A mente que julga a experiência sensível retira dela alguns elementos que provêm da própria experiência interior e, paradoxalmente, para realizar tal juízo e análise, ela não pode depender da experiência sensível. Por isso, a mente, antes de qualquer juízo e análise, ela deve primeiramente se autojulgar. A presença da mente a si mesma constitui o modelo de qualquer substância. Por isso, a mente deve reconhecer, antes de tudo, que é mestra de si, não porque pode usar da sua capacidade de formar imagens, mas por causa da sua própria natureza ontológica, a qual é anterior a cada experiência da realidade sensível reconhecida como tal. Essa natureza ontológica é também ativa no sentido da práxis: Cogito, sum.

\subsection{Leis da lógica e avanço científico}

A mente que se dedica às leis lógicas exercita a própria natureza; está em ato e perfeitamente unida a ele. Com efeito, as leis lógicas são, por essência, de ordem tautológica: 
começa a desenvolver o princípio de unidade nos princípios de não-contradição e terceiro excluído e, depois, na condução das conclusões de uma argumentação às suas premissas. Por paradoxal que pareça, a lógica exprime a unidade espiritual daquilo do qual ela não constitui o princípio ontológico. Inúmeras realidades são conduzidas à identidade formal pela lógica, mediante uma ordem nocional a elas imposta por um projeto mental. A mente que emprega a lógica manifesta as leis da sua própria natureza racional. Realmente, a lógica "fenomeniza" a natureza ontológica da razão que expõe a sua própria estrutura em ato presente a si e nela se exprime. Aqui se baseia a estrutura de toda proposição predicativa que tem alguma pretensão de verdade. A mente exercita sua natureza ao abraçar as relações que constituem cada elemento do universo em particular, quando progride em direção do inteiro universo e cruza todos esses elementos ordenados a priori, compreendendo-os como expressões adequadas de uma identidade que tem como arquétipo a própria natureza em ato. $\mathrm{O}$ pensamento lógico é o fenômeno da mente em ato que tudo abarca. Mas esse fenômeno não é "meu", não é de ninguém. Ele é uma característica da natureza, compartilhada por todos os entes que gozam da razão ideal. A esse ponto, cada cogito desaparece e, com isso, cada realidade singular.

Quando à possibilidade de um implante artificial de uma mente identificada ontologicamente com as expressões lógicas - de uma mente da qual a lógica não seria o fenômeno, mas a essência - é colocada em dúvida pela singularidade do pensar em ato e, ainda, pela historicidade da razão. A razão não é eterna. Por certo, existem regras lógicas que valem eternamente, mas são todas sem conteúdo. Verifica-se, por exemplo, que o princípio de não-contradição é absolutamente necessário e resistente e, nisso, incontrovertível; ele é exercitado no exato momento em que se deseja negá-lo; mas esse princípio constitui apenas uma regra formal, que não explicita qualquer realidade em si definitivamente contraditória ou não. Ora, a prática do saber manifesta que o progresso do conhecimento dispensa a ostentação do verdadeiro e do falso; que constantemente uma verdade se transforma em falsidade; que "aproximar-se de" é mais fecundo do que uma definição delimitada por uma evidência unívoca. O próprio progresso da ciência passa de um paradigma a outro: contesta o saber anterior para remodelá-lo. Identificar a mente com a razão lógico-formal seria, então, ignorar a efetividade do seu compromisso com as próprias investigações e expressões.

Além disso, se o modo da posse de si fosse redutível apenas à razão lógica submetida ao princípio de não-contradição, o logocentrismo ilustrado da centralidade da proposição, e não do juízo, seria a medida da realidade. Mas essa posição, que a historicidade da ciência revela como ingênua, é atualmente insustentável. O progresso científico tem demonstrado isso 
desde o nascimento da Modernidade, quando se retira a terra do centro do universo em favor do sol e, posteriormente, o sol em favor de um ponto que não constitui mais qualquer ponto... O universo não conhece mais uma referência central; quando se fala da sua expansão, não se pode mais indicar a partir de que pondo se poderia medir a sua nova extensão. Mundo, espaço e tempo não têm mais medida absoluta disponível sensivelmente que seja representável. O termo "expansão" ficou tão obscuro quanto o termo "infinito". Hoje se sabe que o logos não é o centro de um sistema estável. As experiências em física atômica de Louis de Broglie e, depois, as relações de incerteza de Werner Heisenberg salientaram o quanto a lógica clássica se tornou incapaz de dizer o que é. Ela era, de fato, elaborada a partir de uma referência linguística e experimental evidentes para aquela época, mas hoje se tornaram obsoletos. Em contrapartida, a epistemologia do século vinte atacou profundamente o sentido clássico da autoconsciência ocidental. Surgiu a suspeita de que o logos, expresso numa proposição que se pretende definitiva, se engana. Suspeita-se, então, da existência de qualquer logos no início. Inicial mesmo é a ação. Não existe mais qualquer proposição que se pretenda inicial, mas um ato cuja racionalidade se tornou irrepresentável.

\section{LINGUAGEM E DIFERENÇA}

O logos não é exatamente a origem. O logocentrismo europeu não pode mais fundamentar tamanha prepotência. É claro, tudo é linguagem, exceto a própria linguagem, diríamos imitando o ditado escolástico sobre o saber. A reflexão contemporânea vai em direção da compreensão de um logos que é precedido por uma ação, passivo e expressivo. Provavelmente terá sido Freud quem mais tenha insistido sobre esse aspecto do nosso ser: a consciência se engana ao desejar que os significados mais claros e evidentes sejam os mais verdadeiros. A hermenêutica das culturas, na antropologia científica, continuou nessa mesma direção. Os significados verdadeiros são, na realidade, inacessíveis a uma leitura imediata e superficial das nossas expressões. Ademais, surge a ideia de que mesmo a ciência, também ela, não seja uma interpretação absoluta do mundo. Obviamente, cada tipo de discurso terá sua forma específica de expressão. Distinguem-se, por exemplo, o mito, que se preocupa com a origem do mundo e com a sociedade, e a ciência que promove os projetos dos cientistas. Por isso, alguns pensam que o relato mítico precede o discurso científico e que a ciência assume os mitos purificados de acordo com as suas normas racionais. O mito animaria as fontes da razão. Ele exprime aspectos da humanidade dos quais o $\operatorname{logos}$ científico não poderá se 
apropriar, a não ser mudando-os e empobrecendo-os. Afinal, não há como analisar a origem objetivamente, como se fosse algo que estivesse à disposição do olhar indiscreto do analista; sua abordagem só pode ser hermenêutica, jamais científica.

\section{1 "Realidade" na história da filosofia ocidental}

Mas, então, o que será a realidade? Iniciando com uma resposta negativa, diríamos que ela não é unicamente o objeto das ciências dos Modernos. O conceito de objetividade deve ser repensado para além da oposição moderna entre sujeito e objeto, entre imanente e transcendente, entre interioridade e exterioridade; da preocupação com a certeza enquanto resultado das formas lógicas do discurso. É preciso, ainda, ir além das perspectivas da Antiguidade remodeladas pela Modernidade (é impossível pular sobre a própria sombra: somos filhos dos Modernos e esses, da Antiguidade). A nossa proposta, centralizada na distinção entre Antiguidade e Modernidade, é a seguinte. A primeira pretende apenas descrever o mundo evidenciando seus elementos mais simples, os conceitos fundamentais que nos permitem construir uma representação sistemática de conjunto. Por sua vez, a Modernidade quer mesmo é se confrontar com a realidade, apanhá-la para, depois, manipulando-a melhorá-la. Outra é a perspectiva contemporânea; é mais atenta ao mistério que habita a realidade e, nesse sentido, ela está mais próxima da Antiguidade, independentemente se essa aspirava conhecer as estruturas mais gerais da realidade e menos a realidade em si mesma. Para a contemporaneidade, a realidade é um mistério; não se exaure na linguagem direta. Hoje, mais que nunca, estamos cientes dos limites do saber científico. Assim, somos uma espécie de kantianos convencidos pela história das ciências e de suas consequências sobre o homem, mesmo se não renunciamos a conhecer sempre mais as coisas. Não se pode declarar que a nossa época seja irracionalista, nem quando essa entra em contradição com o racionalismo clássico das Luzes, hoje, sabidamente muito fraudulento. Ficamos menos ingênuos e mais atentos, abertos ao que verdadeiramente é.

Contudo, poder-se-ia propor outra leitura complementar da história do Ocidente com base nas três etapas ilustradas pelos transcendentais clássicos: o verdadeiro, o bem e o ser ${ }^{4}$. A época clássica se dedicaria mais ao verdadeiro que ilumina as coisas do mundo e ao homem que as acolhe. A época moderna, ao invés, se interessaria antes pelo bem, pelo que se pode realizar para tornar a vida humana mais digna do homem e de sua razão. Já a nossa época

\footnotetext{
${ }^{4}$ Ver Brague (2005, p. 33-47).
} 
atual se vê na obrigação de pensar a sobrevivência do homem no mundo, pensar em nosso ser e no ser do mundo. As problemáticas ecológicas não são folclóricas, como não o são as pesquisas científicas e éticas sobre o dom da vida. A pergunta sobre o ser se transformou em uma questão universal e conscientemente compartilhada. O saber, como se deu a partir da Modernidade, não pode mais ir adiante sem se autolimitar; não se pode mais imaginar que ele sirva ao bem do mundo e do homem sem restrições e sobras.

Contudo, mesmo assim, não podemos voltar aos Gregos e aos Medievais; seria insensatez tentar conhecer a época que precedeu a Modernidade como se essa não filtrasse aquela. A contribuição da Modernidade, seu sentimento de reponsabilidade no pensar e organizar o mundo não pode ser cancelado; deve, sim, ser aprofundado. A realidade não é doada para que o homem faça dela o que pensa ser o mais útil para si; também o cogito é “doado". A mística do pensamento contemporâneo é assinalada pela recusa do racionalismo moderno de maneira tal que não podemos confundir com o agnosticismo. Antes, a mística do pensamento contemporâneo convida a reconhecer um fundamento na raiz de nossos atos, um fundamento que não podemos determinar com normas das coisas do mundo. Não somos como as coisas que articulamos mediante o princípio de causalidade, no qual o efeito se produz inevitavelmente em continuidade com a causa. A necessidade absoluta da relação causal é hoje posta em dúvida, exatamente quando se tem presenta a complexidade do homem. Afinal, o homem não é só um efeito necessário de algumas causas cientificamente aceitas!

\subsection{Contemporaneidade: a época das diferenças}

O nosso tempo é a época das "diferenças". Os períodos anteriores não ignoraram totalmente essa temática, mas estavam num mundo que não é o nosso. Hoje, mais que nunca, somos cônscios da fragilidade do homem, das ameaças que pesam sobre nosso ser, sobre o próprio ser. Para os antigos, o homem era um microcosmo do macrocosmo; lia-se o livro do universo em paralelo com a natureza do homem; as leis da lógica eram, por isso, as leis do mundo. A antropologização do cosmo acontecia por si, sem, contudo, esconder o dinamismo do intelecto humano, do voús orientado para a transcendência. O mundo era ainda pleno de deuses. Dessa forma, contemplar o mundo colocava em movimento a melhor parte da mente humana que se sabia mais digna do que a parte física, sensível, ligada ao mundo que passa e perece. A inscrição do templo de Apolo, em Delfos, gnoti seauton, convidava a reconhecer a participação do sábio em um universo cujas regras não estão à altura de sua sensibilidade, 
tendo a hybris sempre em seu encalço; por isso, Delfos convidava essencialmente à modéstia. O homem, no qual ecoa a totalidade do macrocosmo, é apenas um microcosmo. A consciência de si, a autoconsciência, não ignorava essa situação ontológica, ambígua. Os deuses chamavam à consideração do mistério do homem como mestre de si, mas, ao mesmo tempo, dependente do mundo. A fragilidade da vida humana era posta em evidência pelos heróis. A sabedoria consistia em adaptar-se corajosamente à sorte dos acontecimentos.

Com os modernos, a consciência de si assume nova forma; torna-se expressão quase perfeita da hybris grega. O mundo, desencantado, se passou a ser objeto à disposição do gênio. Cabe ao homem homenagear sua própria natureza e mudar aquele mundo perigoso, cheio de fantasmas, de doenças e de deuses vilões. É claro que a morte permanece como destino de cada indivíduo, mas o trabalho da razão lhe assegura certa permanência, para não dizer uma ascendência sobre o saber que virá. A autoconsciência moderna, que ultrapassa todo tipo de limite, tem orgulho de si, da autonomia do gênero humano, mesmo genérica; dispõe do mundo como se ele fosse um objeto tratável metodicamente para se atingir alguma meta boa para todos. Contudo, cada qual dos modernos era abandonado à tragicidade do próprio existir: não é de se desprezar o fato de que, poucos anos depois de Montaigne, os grandes textos de Descartes se apresentem como autobiografias cheias de inquietude.

A autoconsciência contemporânea é ainda outra com relação à moderna que, por sua vez, era outra com relação à grega. Hoje em dia, a consciência individual reconhece sua fraqueza e dependência; a Modernidade e sua ciência não iludem mais. A pretensão da consciência mestra de si, esplendidamente expressa pela lógica formal, foi desmontada. A autoconsciência não tem mais qualquer força de coação. Agora, o significado contemporâneo de realidade se modifica. A realidade não é mais o que resiste como fato válido para qualquer mente.

A filosofia contemporânea descobre a intersubjetividade, e as diferenças ali intricadas, como condição da realidade e modelo susceptível para guiar a reflexão a fim de que possa colher o sentido ontológico do que é. A própria experiência lógica, que surge da eficiência da linguagem e da reflexão, é considerada como um dos aspectos da complexa realidade da interlocução; à lógica se ajunta a semântica (que nos remete para a história das culturas que se cristalizaram nos termos recolhidos pelos dicionários). Não existe linguagem efetivamente falada sem interlocutores relacionados entre si e em mediações linguísticas historicamente construídas. O lugar mais fundamental da linguagem não é, portanto, o logos lógico, - que pertence ao reino da ratio que calcula, neutra, de ninguém -, mas o logos falado por alguém 
que é escutado por outrem. Essa relação envolve um aspecto retórico que abrange a vida das paixões.

\section{PAIXÃO E REALIDADE}

Por "paixão", intendemos, aqui, o modo como gerimos nossas relações com nossos interlocutores, uma amostragem que exprime o nosso ser e a nossa autoconsciência diante deles. Diverge, desse modo, da lógica formal clássica, a qual constitui um modo de fala que não considera o ser dos interlocutores; ela se quer apática, sem pathos, eficiente a ponto de não considerar as diferenças existenciais dos interlocutores; dela se espera que funcione por si, como uma calculadora. Mas não existirá, então, qualquer possibilidade para alguma paixão na pesquisa lógica? Apesar do exagero formal, a tradição racionalista apostaria que sim. Aliás, seria possível encontrar algum lógico que não se “interesse” pela lógica?

\subsection{Interlocução e resistência}

Não existe linguagem efetiva sem o empenho de um interlocutor alí ativamente envolvido com toda a sua sensibilidade e com a vontade de entender bem o outro. Emerge, aqui, uma forma original, talvez a mais originária, de realidade. Como dissemos anteriormente: a realidade é o que resiste; a realidade física resiste e também resiste o cogito... Mas o que poderia resistir mais do que um interlocutor livre que solicita a minha livre atenção a fim de que eu nada perca do que ele intenta me dizer? O conjunto de atos dos interlocutores envolvidos numa efetiva troca de palavras constitui a mais consistente realidade. A realidade fundamental é, ao mesmo tempo, o ato de outrem que se endereça a mim e o meu ato de estar atento, colocando em suspensão minhas determinações. Um interlocutor pode evidentemente impor-se com violência sobre outrem, mas, no fundo, ele jamais terá sucesso sobre uma pessoa que não se submete à sua investida; ela pode dizer "não" e voltar as costas, levar na brincadeira ou até fingir que consente. A liberdade dessa pessoa é integral; ela possui a liberdade originária do "tu". Esse poder de outrem que limita a potência do meu ato, ao mesmo tempo, o torna possível.

O rigor da lógica também me limita, mas apenas aparentemente, pois ele também me universaliza e faz com que a minha expressão possa ser retomada universalmente. Ao obedecer às leis lógicas, que se impõem a todos e é por todos aceita, e ao assumir a 
necessidade de não dizer de qualquer modo o que pretendo dizer, consigo me expressar de modo tal a se produzir um evento para os outros, um evento de uma comum compreensão. Além disso, se a lógica limita a criação de sentido, ela não impede a inventividade metafórica apesar de trair a lei da univocidade dos termos; o logos se abre assim para novos espaços. Mesmo se à criação poética convenha permanecer dentro de alguns limites para que seja entendida, mesmo se a metáfora deva obedecer a alguma lógica específica, ela goza de tamanha flexibilidade a ponto de permitir a criação, por exemplo, de um estilo pessoal.

Contudo, em nossos dias, não obstante à flexibilidade contemporânea, continua ainda pretensão de se conduzir o discurso para a lógica pura, reproduzindo assim certa mentalidade "globalizante". Na lógica, cuja forma é tautológica, desaparece a singularidade: todos os indivíduos são reduzidos ao uno. Essa racionalidade, resultado de uma radical abstração mental, substitui as realidades e as dilui numa virtual idealidade insensível. Adotar essa forma, por paradoxal que pareça, possibilita, mesmo assim, a interlocução. Graças à sua estrutura ontológica de inter, graças à essência de mediação que nela se encontra, a forma abstrata se torna "intermediadora", o que é bem mais de um simples traço entre dois polos distintos. A forma inter funciona como verdadeira mediação - nisso consiste a sua específica realidade. Mas, quando se separa da sua origem, a forma abstrata passa a funcionar como "meio" autônimo, agora não mais determinado por aquilo que medeia, logo, nada mais medeia. A razão que funciona apenas com formas abstratas se torna, imediatamente, violenta, pois, de modo inevitável, descarta por completo as realidades mediadas (e se descarta a si mesma). Agindo assim, a razão impõe a todos a solidão de sua unicidade e a impossibilidade de ser compreendida.

De qualquer modo, a conceitualização não é o primeiro momento de acesso à realidade, tampouco o é a experiência sensível quando é isolada da elaboração racional. $\mathrm{O}$ coração do saber sobre a realidade, o lugar em que ela aparece e se fenomeniza é, ao invés, constituído pelo encontro de interlocutores. Não se trata, porém, de se reduzir a reflexão na ética. O encontro intersubjetivo, além de originar a ética, é também um evento transcendental, necessário e resistente que envolve a linguagem e, logo, todas as nossas forças mentais. Desde sempre, a tradição filosófica conhece uma estrutura de encontro dos diferentes: a intencionalidade, em que os diferentes permanecem o que são e, ao mesmo tempo, estão também relacionados entre si. A metafísica moderna colocou em evidência a tensão que define esse processo numa perspectiva intelectual, ao acentuar que "algo", um objeto a ser conhecido, sempre se apresenta ao horizonte da intencionalidade. Ora, salienta a filosofia 
contemporânea, esse "algo" não se separa do movimento intencional para o qual tende. Eis porque, para a filosofia contemporânea, semelhante movimento deve ser interpretado como uma resposta da mente à chegada interlocutória da "coisa" que, provocante, permanece outro fundamentalmente.

\subsection{Paixão: experiência originária}

Nesse sentido, evidencia-se a "dadidade" do ente real, cuja realidade se torna manifesta, se "fenomeniza"; perceber sua presença e, ao mesmo tempo, perceber que não somos nós que a colocamos; a realidade é que se coloca diante de nós, nos surpreende e excita nosso desejo de a ela corresponder. A “dadidade" sugere, então, uma "doação" do ente. Mas o movimento espiritual do saber não é bem expresso mediante o vocabulário genérico da intencionalidade. De fato, a abertura intencional ao que é frequentemente acaba por negar a estranheza do fenômeno (é o caso da Modernidade, em geral), reduzindo-o à normalidade desejada pela inteligência, às formas que aprisionam em seus limites o que aparece. O grande problema é que o movimento estático da intencionalidade espiritual não se interpreta corretamente quando ele define o seu horizonte apenas mediante as forças abstratas. Ao contrário, é uma condição ontológica do saber que as realidades sejam também reconhecidas respeitando suas diferenças ou suas respectivas identidades. Não se pode ignorar a unidade do mundo na qual essas diferenças efetivamente se conciliam, mas, também, não se pode ignorar a realidade das diferenças. A esse ponto, impõe-se o grande problema de se saber como o espírito humano conhece essa regra e sabe que respeitar o que é constitui um bem em si, sem, contudo, negar a necessidade intelectual do "uno". Em outros termos, de qual experiência se retira um saber assim tão essencial?

Nossa hipótese é que a paixão seja a experiência originária do conhecimento. Mas, para sustentar tal hipótese, seria necessário especificar melhor o que se entende por paixão; além disso, será preciso insistir na sua estrutura que se realiza enquanto resultado da imbricação de dois aspectos, um ativo e o outro passivo. A paixão é obviamente operativa, ativa, mas apenas em resposta à solicitação do que é. Na perspectiva dessa estrutura, paixão e emoção se assemelham, mas cada qual possui sua particularidade. A emoção age sobre o psiquismo do sujeito até o ponto de bloqueá-lo e impedir qualquer tipo de reação. A paixão, pelo contrário, provoca ação, incita a se considerar a coisa provocadora e a dar-lhe uma resposta com vivacidade. É claro que a resposta será dada de acordo com a potência da 
emoção anteriormente sofrida. Tal perspectiva, no entanto, nos leva a reconhecer certa inversão no vocabulário habitual: o termo "emoção" parece realmente significar um movimento do "eu" convocado a ir para fora de si mesmo; já o termo paixão evoca muito mais uma passividade. Contudo, foi o uso linguístico o responsável pela inversão de tais sutilezas interpretativas, inclusive adicionando alguns elementos temporais que tais termos não expressam diretamente. A emoção surge no mesmo instante em que é provocada, na presença do que emociona. A paixão age de modo mais duradouro; aliás, pode até desconsiderar a duração do que é emocionante. A emoção possui, então, um aspecto físico e acidental que a paixão, por estar distante do que é, praticamente desconhece. Essa distância pode inclusive produzir eventual verificação da emoção sofrida, confrontando-a de modo metódico com a realidade vivida na continuidade temporal da paixão ${ }^{5}$.

É necessário especificar melhor tais considerações. Precisamos identificar qual tipo de paixão é mais capacitada para confrontar a realidade e exprimir com mais exatidão o surgimento do espírito na realidade. São inúmeras as paixões, como bem mostram as meditações dos filósofos e as pesquisas na área da psicologia. Descartes atribui à admiração o primado das paixões; já para Spinoza, a primeira de todas é a alegria, em sentido positivo, e, em sentido negativo, o medo. O cristianismo, por sua vez, dá primazia ao amor (também nossa cultura contemporânea dá proeminência ao amor, mas com intenso significado erótico certamente conduzido pela indiferença do individualismo moderno). O amor cristão é, diversamente, intencional e atento, é relacional. Na tradição filosófica, à realidade "objetiva" corresponde uma intencionalidade "subjetiva", espiritual, que a Idade Média identificava, no âmbito da afetividade, com o desejo. Nesse período, o conhecimento estava envolvido por uma atmosfera de insatisfação: um dinamismo que jamais termina ${ }^{6}$. Alguns autores neoescolásticos suspeitaram que a assunção do desejo como elemento fundamental do conhecimento escondesse algum voluntarismo, confundindo, assim, os modos do afeto e da vontade numa unidade psicológica da qual a razão cognoscitiva seria o princípio. Tal suspeita, porém, revela muito mais o racionalismo exagerado da Modernidade de autores que confundem o conhecido, o "objetivo", com o desejo e a vontade, os quais não pertenceriam à razão "objetiva".

\footnotetext{
${ }^{5}$ Sobre esse tema, há um interessante artigo de Paolo Fiorini (2007) em que se evidencia a originalidade da temporalidade e do "evento" como natureza da paixão.

${ }^{6}$ Sobre o entusiasmo, ver Caraluddi (2007).
} 


\section{COMPAIXÃO E DIFERENÇA}

Nem todas as paixões exprimem o essencial do espírito. Por esse motivo, os autores estabelecem hierarquias entre elas. Habitualmente, o espanto é considerado a paixão que gera a reflexão filosófica. Porém, como sustenta Aristóteles, ele anima sim a capacidade intelectiva do homem, mas logo se dissolve, exatamente quando se soluciona o problema que o originou. O espanto é, então, provisório e, portanto, não pode ser originário ${ }^{7}$. Recentemente, com $\mathrm{Ser} e$ tempo, Heidegger pensou a angústia como paixão originária, até se tornar, com o existencialismo, paixão do absurdo. Ricoeur, por sua vez, dizia que o sentimento de injustiça estimula o despertar da razão, revelando a sua verdadeira tarefa ou seu verdadeiro telos: a justiça.

\subsection{A compaixão na história da filosofia}

De minha parte, avento sustentar que a paixão mais ontológica é a compaixão. Contudo, não se pode levar adiante tal hipótese sem considerar que a interpretação filosófica tradicional referente à compaixão, consagrada pela definição do Estagirita, se opõe a esse projeto. Segundo Aristóteles (Retorica, II, 8, 1385b 8), compaixão (eleos, que traduz também "misericórdia" ou "piedade") é "certo pesar por um mal que se mostra destrutivo ou penoso, e atinge quem não o merece, mal que poderia esperar sofrer a própria pessoa ou um de seus parentes, e isso quando esse mal parece iminente".

Salientemos alguns pontos da definição aristotélica. Em primeiro lugar, a compaixão não nasce de uma visão positiva (talvez, nesse caso, se identifique muito mais com a inveja), mas da constatação da falta de algo que seria devido, e cuja ausência, não merecida, não derivaria da essência da natureza. O ponto que Aristóteles pretende atingir com a compaixão parece, então, outro: tudo o que representa aquela visão penosa poderia acontecer comigo. $\mathrm{O}$ critério da compaixão é, então, a imagem que faço de mim mesmo e do meu futuro, dos riscos que corro na minha vida; e, sendo assim, nada há aqui que seja ontológico, fundante. David Hume proporá uma doutrina muito semelhante: "apenas da imaginação depende a piedade"»8.

Para deveras me abrir à realidade, eu deveria ignorar a paixão que só diz respeito a

\footnotetext{
${ }^{7}$ Existiriam, aqui, muitas nuances a serem assinaladas, mas permaneceremos nas linhas gerais dessa perspectiva. Para maiores aprofundamentos, ver Petrosino (1997).

${ }^{8}$ Ver texto de Hume (2001, p. 389), no livro II, cap. II, § 7, em que ele discorre sobre a compaixão.
} 
"mim". O tratado Sobre a clemência, que Sêneca escreveu para chamar a atenção de Nero, acrescenta um importante detalhe. A compaixão e a crueldade se opõem como duas situações igualmente exageradas: a compaixão seria uma clemência exagerada, e a crueldade uma exagerada severidade. Aqui, a perspectiva é política, o que fornece à reflexão certa atenção para com a sociedade, e vai além do indivíduo isolado. $\mathrm{O}$ ideal de um bom governo é agir com clemência e severidade, sem exageros; em todo caso, a mansidão será, porém, melhor do que a crueldade. Todavia, a misericórdia não honra as grandes almas; ela é um serviço específico de almas decadentes, atingidas pelos males alheios. O poder político é clemente enquanto possui uma norma racional, deixando a compaixão e as lágrimas às velhotas, pois a tristeza "fere a mente, a atinge, a retrai" (SENECA, Sulla clemenza, III, 1, 4), e impede, assim, eficaz auxílio a quem precisa. A indiferença do estoico para com o mal alheio é, então, configurada pela percepção da mediação universal da razão, do logos com suas implicações sociais e políticas.

Descartes especifica melhor essa lição, mas muda o objeto da piedade ${ }^{9}$ : os fortes não têm piedede para com os que sofrem, mas para com quem não suporta sofrer, ou seja, para com quem é radicalmente frágil. A dureza dos estoicos, que chega a Descartes, não nega a piedade, desconhecida pelos malvados e invejosos, mas busca meios para acompanhar os fracos a fim de proporcionar-lhes força no sustento da sorte. De modo semelhante, para Spinoza, a piedade acompanha a tristeza ${ }^{10}$; é, porém, negativa se ela retira a energia da resposta: as lágrimas cegam e impedem ver o bem a se fazer. Spinoza, ao contrário de Descartes, nada de positivo reconhece na compaixão.

Kant sintetiza todas essa ideias ${ }^{11}$. Para ele, é um dever tomar parte no mal alheio, mas é também necessário evitar qualquer participação patológica. Na compaixão, realmente me deixo envolver pela dor alheia, mas por pura imaginação, tornando impossível qualquer auxílio a quem sofre; nessa situação, encontramo-nos, os dois, a sofrer. Ora, é no mínimo estranho pensar que seja um dever aumentar o mal no mundo. Logo, não há como a compaixão estar vinculada racionalmente à moral. Contudo, considerando o fato de que a obediência ao dever pelo dever não é muito animador para o homem comum, sensível, a compaixão acaba sendo vista como sentimento útil para apoiar o trabalho da razão. Só, por isso, torna-se "importante, antes, um dever ir onde estão os pobres, e jamais abandonar a

\footnotetext{
${ }^{9}$ Ver Descartes (Passioni dell'anima, $\left.§ 187\right)$.

${ }^{10}$ Ver Spinoza (Etica, IV, § 50).

${ }^{11}$ Ver Kant (Metafisica dei costumi, II, Dottrina della virtù, § 34).
} 
comiseração" (KANT, Metafisica dei costumi, § 35).

Inverso é o ponto de vista de Schopenhauer, para quem a compaixão constitui um comportamento decisivamente positivo. Para ele, a vida humana conhece um desejo fundamental que é a vontade de sair da privação; mas como são incontáveis as privações, toda a vida é de dor. Conhece-se verdadeiramente alguém, quando se conhece a sua vontade de viver, logo, sua dor. A compaixão é, por isso, um caminho para o conhecimento da essência humana e, nesse caso, possui claro valor ontológico: "todo verdadeiro e puro amor é compaixão, e todo amor que não seja compaixão é egoísmo. O egoísmo é eros; compaixão é

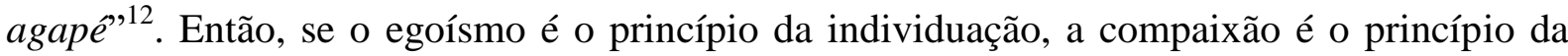
sociabilidade e do conhecimento da realidade.

Nietzsche, de algum modo envolvido por essa perspectiva, critica a posição de Schopenhauer, julgando tratar-se de uma moral de "decadentes" $" 13$, mas com importantes particularidades. Segundo Nietzsche, a grande dor "criou, até agora, toda excelência humana". É preciso, sim, amar a dor que educa, mas sem a compaixão que adocica. Os ditos benfeitores que buscam extinguir a nossa, "mais do que nossos inimigos, diminuem o nosso valor e a nossa vontade" ${ }^{\prime 4}$. Falta pudor à compaixão ${ }^{15}$, ela é prática de niilismo ${ }^{16}$. Nesse aspecto, Nietzsche retoma algumas teses de Descartes.

\subsection{Empatia, alteridade e compaixão}

A tradição filosófica assumiu habitualmente a compaixão a partir de um ponto de vista prático, por vezes também ético, quando se tratava da relação com outrem, e Schopenhauer vislumbrou, aqui, uma dimensão ontológica. No entanto, o problema é o de saber se é possível efetivamente algum conhecimento de outrem. A alteridade, posto ser alteridade de outrem, não impede real e radicalmente o conhecimento? O conhecimento não estaria sempre submetido à lei do uno, à forma abstrata comum?

Eis o problema da "empatia", cujo termo evoca a palavra "compaixão". Edmund Husserl e sobretudo Edith Stein, que se interessou particularmente pela empatia, modificaram profundamente a orientação da reflexão filosófica, graças à fenomenologia que se dedica à

\footnotetext{
${ }^{12}$ Ver Schopenhauer (Il mondo come volontà e rappresentazione, IV, § 67): “o puro amor é compaixão".

${ }^{13}$ Ver Nietzsche (Al di là del bene e del male, \$ 225).

${ }^{14}$ Ver Nietzsche (Gaia Sapere IV, § 338).

${ }^{15}$ Ver Nietzsche (Zaratustra, II, I compatenti).

${ }^{16}$ Ver Nietzsche (Anticristo, $\S 7$ ).
} 
pura ideia dos noema pensados. Por muitos aspectos e com frequência, a tradição considerou a compaixão sob um ponto de vista utilitário, logo, não em si mesma. A fenomenologia é bem mais original ao considerar a essência do que examina, nesse caso, ele está atenta à essência da alteridade implicada na essência da compaixão.

Contudo, a reflexão não alcançou sua maior profundidade com Husserl, cuja preocupação era ainda epistemológica e avaliada a partir da experiência do "eu". Seu problema, particularmente na quinta das Meditações cartesianas, era o de saber como se pode conhecer a outra pessoa enquanto pessoa. Mas a problemática se desenvolve com o prejuízo de que a outra pessoa será, apesar de tudo, uma pessoa "como" eu; dou-me conta da presença de outrem quando essa presença não é de qualquer coisa, visto que o corpo alheio revela algum psiquismo, uma interioridade que se exprime no corpo e de modo mais do que corporal. Ora, segundo Husserl, posso fazer uma diferença entre esses dois aspectos e atribuir um psiquismo humano ao corpo, porquanto essa experiência já a faço em mim. Logo, a minha experiência medeia o conhecimento que tenho de outrem enquanto pessoa humana. A compaixão seria o comportamento afetivo que me permite vincular minha experiência com a da outra pessoa, de visualizar uma analogia de uma com a outra. Coloca-se em dúvida a validade do conhecimento analogicamente estabelecido por essa perspectiva epistemológica de Husserl. Tudo indica que o discurso fracassará e retornará aos dados de uma tradição filosófica comum.

Apesar disso, Husserl insistiu na atenção sobre a alteridade enquanto alteridade e, nisso, ele inovou. A compaixão poderia ser a paixão da ou pela alteridade ${ }^{17}$. Vimos que a experiência psíquica pessoal permite reconhecer que um determinado corpo é o de uma pessoa. Nesse sentido, minha experiência é mediadora entre as pessoas. Contudo, a experiência humana mostra que cada qual apenas reconhece sua humanidade a partir de outrem, e não por si só. Sendo assim, no máximo se poderia dizer que cada qual reconheceu sua humanidade graças a outrem aos modos na anamnesis platônica. Desse modo, quem não se encontra com outrem, não tem acesso à sua humanidade. A experiência dos meninos-lobo evidencia essa constatação. Sendo assim, Stein poderá afirmar que a "minha" experiência psíquica não é originária. Posso até participar do sofrimento alheio, mas não por iniciativa minha; para que eu participe da dor de alguém terei, então, de me envolver no aprendizado do sofrimento alheio.

\footnotetext{
${ }^{17}$ Ver Marion (2003, p. V).
} 


\section{3 Compaixão: a mais ontológica das paixões}

À guisa de conclusão, podemos dizer que na tradição filosófica ocidental a compaixão comumente foi entendida em oposição à razão. Os motivos da ação apaixonada são construídos, como se costuma dizer, pela imaginação e não pelo saber que se pretende racional. Apesar disso, não são poucos os autores, também clássicos, que, depois da redução ao máximo do significado humano da compaixão, a recuperaram posteriormente; começaram a perceber que a exaltação da razão devia agora ser mensurada pela realidade da vida humana, pelos outros homens; como se a concessão àquela anterior ideia de razão fosse, de fato, insuportável, porque puramente ideal. Ademais, tornou-se normal para a tradição filosófica deixar de lado a essência da interlocução no que tange à interpretação que faz do dinamismo do saber. A compaixão, nesse caso, aparece muito mais como uma paixão suscetível de ser reduzida a meras dimensões imaginativas do que assumida como uma virtude atenta à realidade. Pelo contrário, a compaixão presta atenção ao que é mais real de tudo, mais resistente, presta atenção à liberdade alheia em que cada realidade adquire sentido.

Não se pode negar que a compaixão corre muitos riscos de se processar na ilusão e, certamente, graças à imaginação. Mas, se a compaixão constitui o comportamento que permite corresponder adequadamente à chamada alheia, ela não pode ser regulada apenas pela possibilidade de relação que parta do potente e vá à direção do impotente. A escuta de uma resposta é medida por quem chamou, pelo seu grito, em especial, por sua dor proveniente da incapacidade de ser por si e para si. Quem se compadece deve se disponibilizar tão-somente para corresponder a uma chamada; e, para isso, é desnecessário colocar em evidência sua capacidade o socorro, a sua riqueza. A atenção solicitada por quem sofre não pode estar vinculada aos meios de potência. A compaixão exige, ao invés, uma correspondência à dor de outrem de ser. Um socorro que apenas aplaca uma indigência ignoraria a radicalidade da origem de cada solicitação de ajuda; essa seria uma ajuda profundamente injusta, pois conduziria o sofredor a sobreviver com os meios que o poderoso oferece a partir da sua cultura específica e imaginação de poder. É obvio que a compaixão age para ajudar, mas o problema é o de discernir o modo justo da ajuda oferecida, da ação conveniente. Eis porque a paixão exige longo tempo, uma duração, de acordo com o nosso vocabulário. Essa duração é exigida não apenas para se organizar melhor a resposta e o auxílio, por motivos administrativos. Ela se impõe sobretudo como condição para a atenção ao outro; paciente atenção nos confrontos com o sofredor e consigo mesmo. Pode-se então notar que a 
compaixão, vivida retamente, recusa ser apenas um momento de emoção, embora a emoção possa revelar a profundidade do ser indigente. Outrem é mestre do compadecedor, o qual deve se adaptar à chamada feita a priori, ou seja, deve deixar que se abra em si mesmo o abismo da indigência essencial, da dívida de ser. As reflexões contemporâneas sobre o dom e a gratuidade enquanto estruturas ontológicas têm aqui seu registro.

Kant discorda que essa correspondência ao sofrimento radical de outrem possa ser moral. Nisso, ele permanece moderno, iluminado, na certeza de que o futuro do homem dependa de seu gênio inventivo. O "mal radical" desenvolvido em A religião nos limites da mera razão, não é assim tão radical a ponto de impedir o progresso da humanidade. Éric Weil refutou exatamente essa posição ${ }^{18}$. Dizer que a epistemologia de Kant é moderna, significa confirmar que ela se desenvolve no âmbito do indivíduo genérico. Não aparece, aqui, qualquer singularidade, qualquer ser existente. É tudo estrutural. Mas a moral kantiana sabe que o puramente racional é impossível; é necessário, mas impraticável e, por isso, capaz de gerar o desespero ou a liberação da opressão da razão mediante a rejeição de suas exigências de razão pura. Distante de uma prática efetivamente sensata, Kant então se autoelimina. Por isso, ele próprio sugere a necessidade das pessoas se aproximarem de quem está no mal, uma prática que salvaria sua moral formal que necessariamente se encaminha para a contradição da razão.

Descartes é mais penetrante ao salientar que a compaixão não se direciona para os fatos da miséria humana, mas sim para quem não suporta a própria miséria e, assim, é radicalmente miserável. Contudo, a esse ponto, a compaixão parece se tornar absolutamente inútil. Além do mais, nesse contexto, o que se pode intender por "utilidade"? A inutilidade da compaixão não impede de se estar ao lado de quem sofre, de acompanhar sua indigência de ser e de dar testemunho de certa fidelidade na indigência pessoalmente vivida, uma fidelidade que envolve a mais profunda liberdade, a que sabe e aceita o fato de não ser a sua própria origem, apesar da sua efetividade. Abrem-se, aqui, outros e novos domínios para a reflexão como, por exemplo, o da criação e da afetividade espiritual.

O caminho que percorremos demonstrou o quanto a atividade intelectual depende da interlocução e, logo, da compaixão, na qual experimentamos as estruturas mais fundamentais da abertura espiritual ao real. Alcançamos, com isso, a perspectiva segundo a qual a realidade é, em si mesma, espiritual. A realidade é a morada transcendental dos interlocutores que se convocam mutuamente à escuta e à consolidação de um sentido desejável para todos.

\footnotetext{
${ }^{18}$ Ver Weil (1963).
} 


\section{REFERÊNCIAS}

ARISTOTELE. Metafisica. Milano: Vita e pensiero, 1995

ARISTOTELE. Retorica. Roma: Carocci, 2014.

BRAGUE, R. Da un trascendentale all'altro. In: SERVIZIO NAZIONALE PER IL PROGETTO CULTURALE. A quarant'anni dal Concilio. VI Forum del Progetto culturale. Bologna: Dehoniane, 2005, 33-47.

CATALUDDI, Michele. L'entusiasmo. Unità dilattica di passione e pensiero quale religio. In: GILBERT, Paul (org.). Passione. Indagini filosofiche tra ontologia e violenza. Assisi:

Cittatella, 2007, p. 181-212.

DESCARTES, R. Le Passioni dell'anima. Milano: Bompiani, 2003.

FIORINE, Paolo. Passione e evento. Per una fenomenologia dell'atto di "aver passione". In: GILBERT, Paul (org.). Passione. Indagini filosofiche tra ontologia e violenza. Assisi: Cittatella, 2007, p. 113-154.

GILBERT, P. Corso di metafisica. La pazienza d'essere. Casale Monferrato: Piemme, 1997.

GILBERT, P. Ragione, realtà, compassione. In: GILBERT, P. (org.). Passione. Indagini filosofiche tra ontologia e violenza. Assisi: Cittadella, 2007, p. 155-179.

HUME, D. Trattato della natura umana. Milano: Bompiani, 2001.

KANT, I. Metafisica dei costumi. Bari: Laterza, 2009.

MARION, J.-L. Préface. In: HOUSSET, E. L’intelligence de la pitié. Phénoménologie de la communauté. Parigi: Cerf, 2003, p. I-VI.

NIETZSCHE, Fr. Al di là del bene e del male. Milano: Adelphi, 1977.

NIETZSCHE, Fr. Anticristo. Maledizione del cristianesimo. Milano: Adelphi, 1977.

NIETZSCHE, Fr. La gaia scienza e idilli di Messina. Milano: Adelphi, 1977.

NIETZSCHE, Fr. Così parlò Zarathustra. Un libro per tutti e per nessuno. Milano: Adelphi, 1976.

PETROSINO, S. Lo stupore. Novara: Interlinea, 1997.

RICOEUR, P. La metafora viva. Milano: Jaca Book, 1976.

SCHOPENHAUER, A. Il mondo come volontà e rappresentazione. Bari: Laterza, 2009.

SENECA. Sulla clemenza. Santarcangelo: Rusconi Libri, 2017.

Sapere aude - Belo Horizonte, v. 10 - n. 19, p. 122-144, Jan./Jun. 2019 - ISSN: 2177-6342 
SPINOZA, B. Etica. Milano: Bompiani, 2007.

WEIL, É. Problèmes kantiens. Parigi: Vrin, 1963. 